\title{
Catalytic Removal of Ozone by Pd/ACFs and Optimal Design of Ozone Converter for Air Purification in Aircraft Cabin
}

\author{
Fan $\mathrm{Wu}^{\mathrm{a}}$, Yuanwei Lu ${ }^{\mathrm{a}}$, Mingyuan Wang ${ }^{\mathrm{a}}$, Xingjuan Zhang ${ }^{\mathrm{b}}$, Chunxin Yang ${ }^{\mathrm{b}}$ \\ ${ }^{a}$ MOE Key Laboratory of Enhanced Heat Transfer and Energy Conservation and Beijing Key Laboratory of Heat Transfer and Energy \\ Conversion, Beijing Municipality, Beijing University of Technology, Beijing 100124, China. \\ ${ }^{b}$ School of Aeronautic Science and Engineering, Beihang University, Beijing, 100191, China.
}

Received 19 February 2019; Accepted 12 June 2019

\begin{abstract}
Ozone in aircraft cabin can bring obvious adverse impact on indoor air quality and occupant health. The objective of this study is to experimentally explore the ozone removal performance of flat-type catalyst film by loading nanometer palladium on the activated carbon fibers ( $\mathrm{Pd} / \mathrm{ACFs}$ ), and optimize the configuration of ozone converter to make it meet the design requirements. A one-through ozone removal unit with three different Pd/ACFs space was used to test the ozone removal performance and the flow resistance characteristic under various temperature and flow velocity. The results show that the ozone removal rate of the ozone removal unit with the Pd/ACFs space of $1.5 \mathrm{~mm}$ can reach $99 \%$ and the maximum pressure drop is only $1.9 \mathrm{kPa}$ at the reaction temperature of $200^{\circ} \mathrm{C}$. The relationship between pressure drop and flow velocity in the ozone removal unit has a good fit to the Darcy-Forchheimer model. An ozone converter with flat-type reactor was designed and processed based on the one-through ozone removal experiment, its ozone removal rate and maximum pressure drop were $97 \%$ and $7.51 \mathrm{kPa}$, separately, with the condition of $150^{\circ} \mathrm{C}$ and $10.63 \mathrm{~m} / \mathrm{s}$. It can meet the design requirements of ozone converter for air purification and develop a healthier aircraft cabin environment.
\end{abstract}

Keywords: Ozone; Aircraft Cabin; Optimum Arrangement; Pd/ACFs; Ozone Converter.

\section{Introduction}

The outdoor air pollution and ventilation system pollution are two major factors influencing the indoor air quality [1]. As a special indoor environment, the air quality in the aircraft cabin is more associated with the ambient air conditions and regulated by the supplied outside air [2, 3]. Since the energy crisis of 1970s, commercial airplanes routinely cruise in the upper troposphere or the lower stratosphere where the ozone concentration can reach the level of hundreds of parts per billion ( $\mathrm{ppb}$ ), ozone will enter aircraft cabin with the bleeding air through engine compressors [4]. Ever since, more and more passengers started to complain the poor air quality caused by the ozone [5]. As to short-term exposure, studies have strengthened the evidence that exposure to the over-standard ozone concentration $(>0.1 \mathrm{ppm})$ will increase the mortality and respiratory morbidity rates [6]. Due to the strong oxidizing, ozone can react with the passenger's skin oils and the leather seats in aircraft cabin, which become the important source of volatile organic compounds (VOCs) [7]. Due to the hazards of ozone, the World Health Organization had updated the air quality guideline for indoor ozone that the maximum average concentration cannot exceed $0.09 \mathrm{ppm}$ in 8-hr when people exposure to the ozone environment. The Occupational Safety and Health Administration (OSHA, the United States of American) also required the maximum ozone concentration of $0.1 \mathrm{ppm}$ when human exposure to such environment for

* Corresponding author: uyuanwei@bjut.edu.cn

http://dx.doi.org/10.28991/cej-2019-03091361

(C) 2019 by the authors. Licensee C.E.J, Tehran, Iran. This article is an open access article distributed under the terms and conditions of the Creative Commons Attribution (CC-BY) license (http://creativecommons.org/licenses/by/4.0/). 
8-hr [8, 9]. The U.S. Federal Aviation Administration (FAA) regulations require that the ozone concentration in aircraft cabin cannot exceed $0.1 \mathrm{ppm}$ when flying time exceeds 4-hr. Chinese 'indoor air quality standards' (GB/T 18883-2002) requires that the indoor ozone concentration cannot exceed $0.08 \mathrm{ppm}[10]$.

For meeting the above air quality standards, some types of airplanes have been equipped with ozone converter in the environmental control system (ECS) to reduce the ozone concentration $[10,11]$. According to the data released from European aircraft manufacturer Airbus and Boing Company, the ozone converter is a mandatory device on the long flight commercial aircrafts like A320, A330 and B767, B777, while the rest thousands of short flight airplanes were installed optionally [12]. At present, many aircrafts do not have the air-cleaning facility to remove ozone, so the mean ozone level exceeding $0.1 \mathrm{ppm}$ over the course of flight often occurs. It is obvious that the further technological research and development in the field of ozone conversion is critical to improve the air quality in aircraft cabin [13, 14].

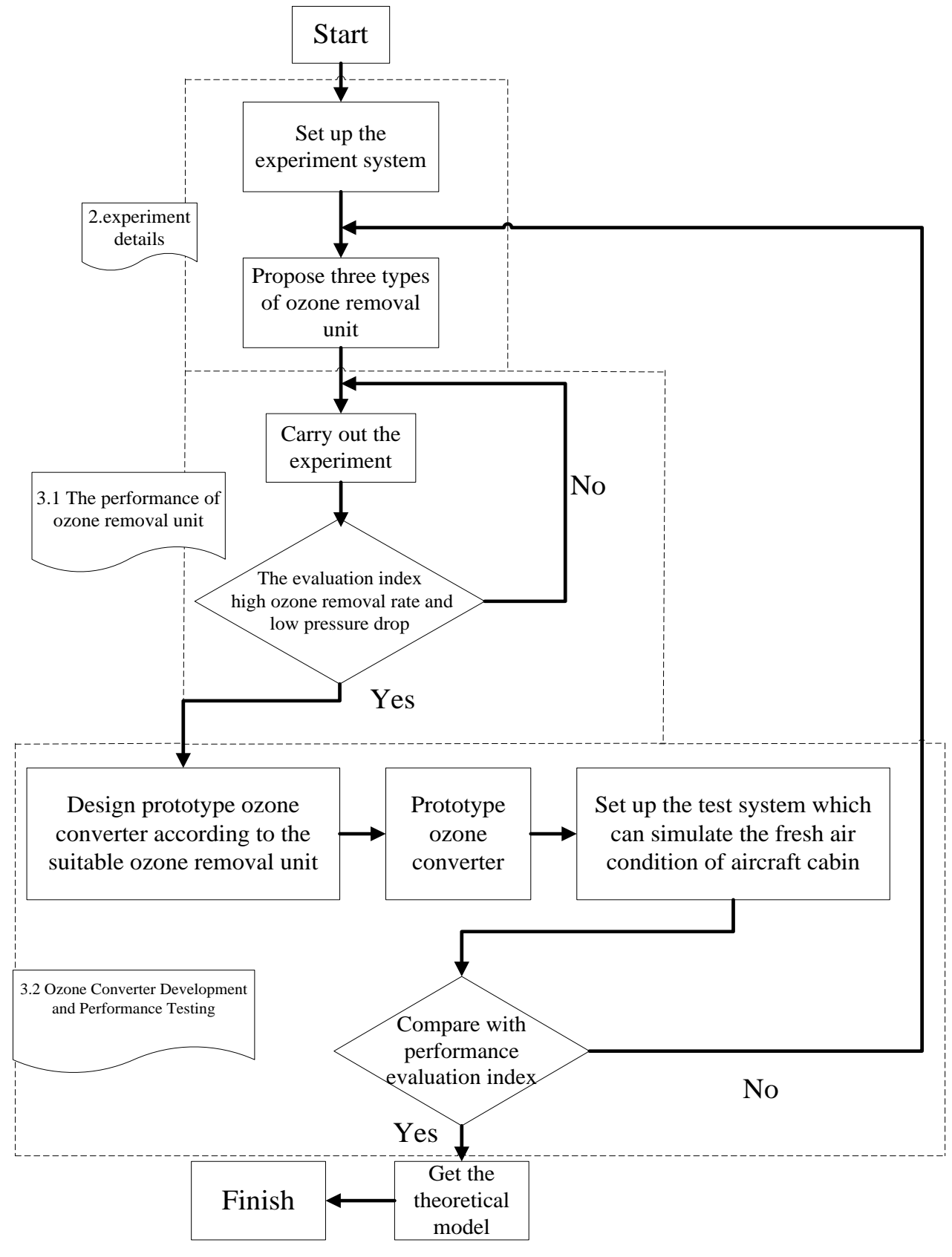

Figure 1. The flowchart of research methodology

Researchers have proposed various ozone removal techniques for ozone removal, such as adsorption [15], thermal decomposition [16], electromagnetic radiation decomposition and catalytic decomposition [17, 18]. Because of the efficiency and economy, catalytic decomposition of ozone is an ideal technique for indoor air purification [19]. Catalytic decomposition consist of thermal-catalytic decomposition and photocatalytic decomposition [20-22]. Lu et.al has experimentally confirmed that the flow velocity of the bleeding air supply to the aircraft cabin is too high to apply photocatalytic technique into the ozone removal in aircraft [10]. Thermal-catalytic decomposition is the more suitable example, because the temperature of bleeding air in the aircraft is closed to $90-200^{\circ} \mathrm{C}$ which can meet the 
temperature requirement for the thermal-catalytic technology [8]. The results in our previous research show that thermal catalytic by coating nanoparticle palladium on the surface of activated carbon fibers (Pd/ACFs) can remove ozone efficiently and ozone removal rate is proportional to flow resistance [23]. Through extensive literature review, very few researches focus on the design of ozone converter and test ozone removal performance under actual working condition of bleeding air from aircraft. It is necessary to focus on the optimization of reactor configuration to reduce its pressure drop and maintain ozone removal efficiency. Figure 1 shows the flowchart of research methodology. The results in this paper can provide the design basis for the application of ozone converter in environment control system of commercial aircraft [24-26].

\section{Experiment Details}

\subsection{Experimental Apparatus}

The experimental system in this paper, which can be used to adjust various parameters, such as initial ozone concentration, flow velocity and experimental temperature. The schematic experimental system is shown in Figure 2.

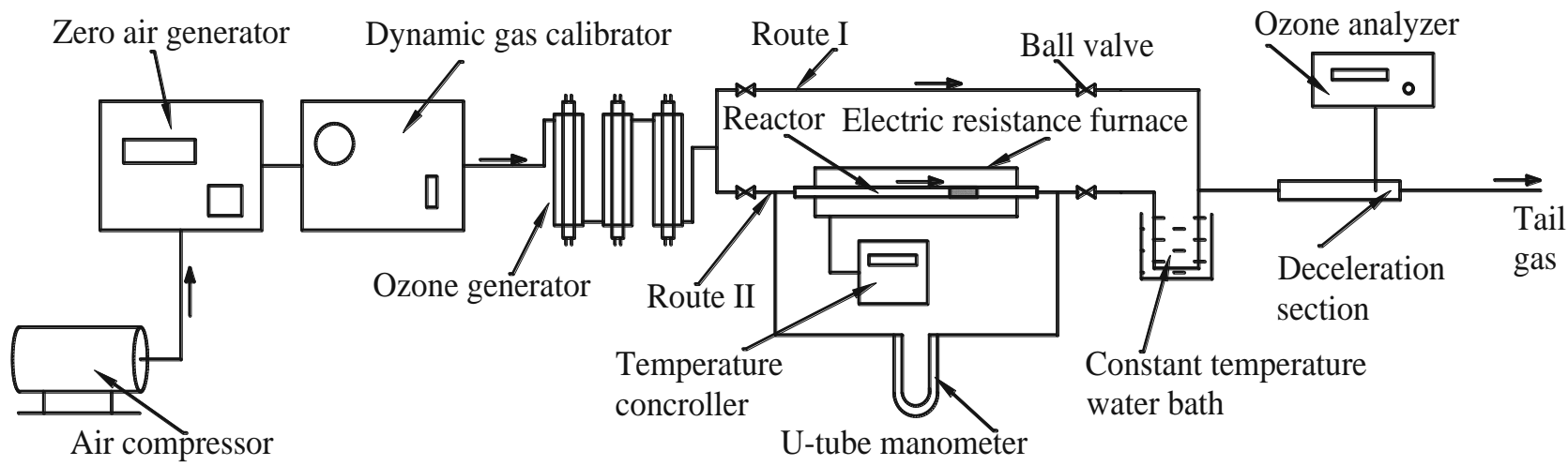

Figure 2. The schematic diagram of the experimental system

An air compressor drove a zero air generator to produce high pressure zero air. A dynamic gas calibrator (Thermo Environmental Inc. Model 146C) was operated with the zero air generator to control the mass flow rate of the zero gas. The ozone generator equipped with three ultraviolet lamps with a primary wavelength of $254 \mathrm{~nm}$ was used to introduce ozone into the experimental system. Before the experiment, the air stream containing ozone flow through the by-pass Route I. When the flow rate and ozone concentration reach steady for one hour, ozone was introduced into the reactor that was placed in the center of the electric resistance furnace.

The reactor (Figure 3) was composed of a transparent quartz glass tube with the diameter of $14 \mathrm{~mm}$ and the length of $100 \mathrm{~mm}$, an ozone removal unit was placed inside it. The ozone removal unit was made of the horizontally arranged catalyst $\mathrm{Pd} / \mathrm{ACF}$ s that was prepared by coating nanometer palladium on the surface of activated carbon fibers with the same process as shown in literature [23]. The performance of ozone removal unit with different Pd/ACFs space was tested.

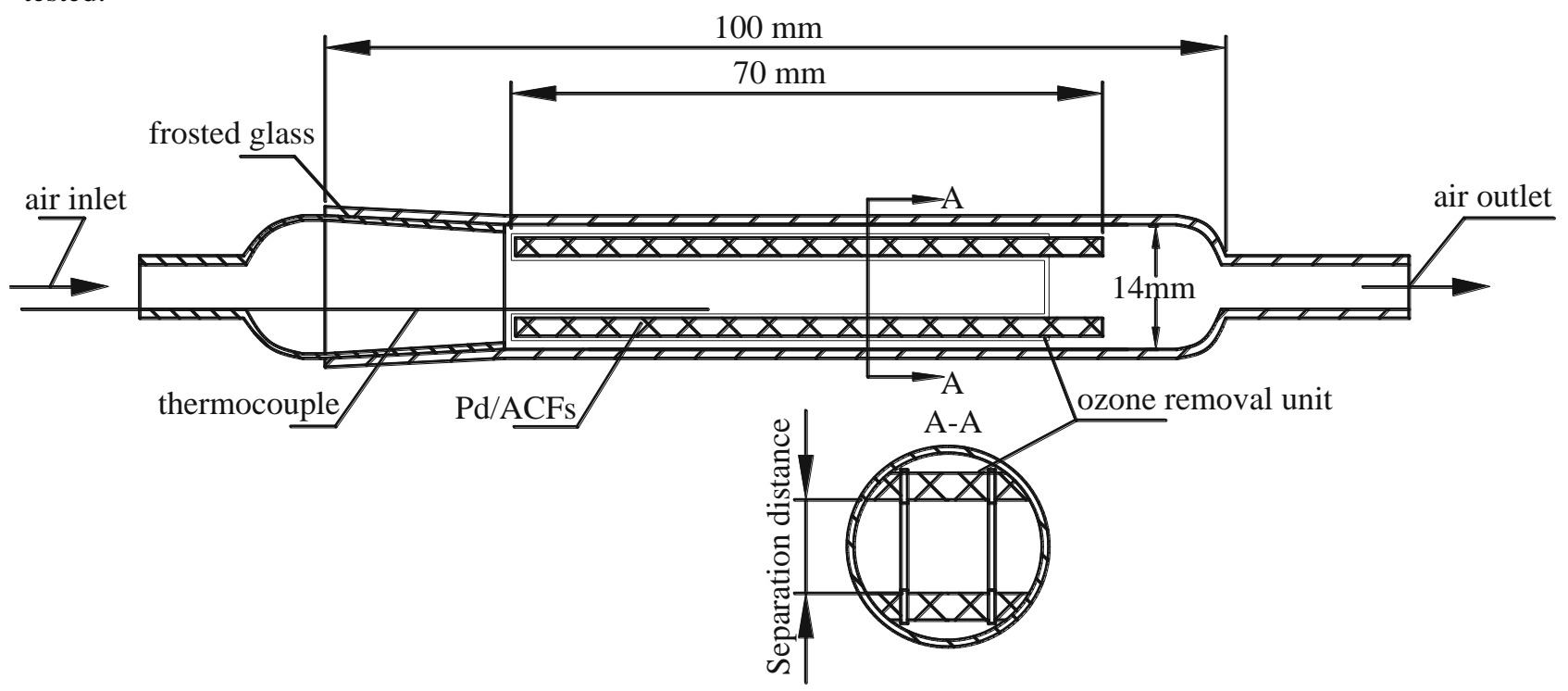

Figure 3. The reactor schematic diagram 
Figure 4 shows the ozone removal unit with the different Pd/ACFs space. In order to meet the reactor dimensions, a $\mathrm{Pd} / \mathrm{ACF}$ fixing device with $60 \mathrm{~mm}$ in length, $9 \mathrm{~mm}$ in width and $10 \mathrm{~mm}$ in height was prepared, as shown in Figure $4(\mathrm{a})$. The fixing device, $9 \mathrm{~mm}$ in width and $2 \mathrm{~mm}$ in height fixed the Pd/ACFs films with the dimension of $70 \mathrm{~mm}$ in length, horizontally. For example, two flat-type Pd/ACFs films were fixed by the space of $5 \mathrm{~mm}$ in Figure 4(b), while three and four flat-type $\mathrm{Pd} / \mathrm{ACF}$ films were fixed with pitch distance of $1.5 \mathrm{~mm}$ and $0.3 \mathrm{~mm}$ (measured by the vemier caliper), as shown in Figure 4(c) and (d), respectively. Due to the fixing device has a little effect on the flow process, so it is represented by the dash line, as shown in the Figure 4 (b-d).

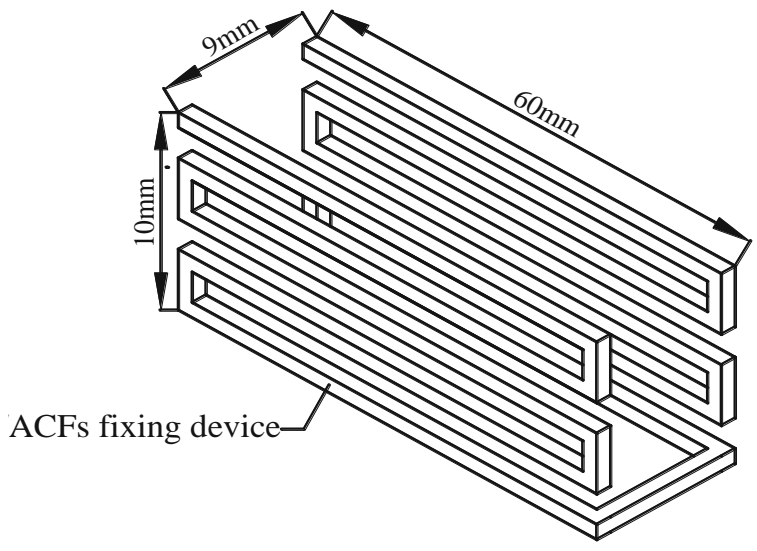

(a) Fixing device

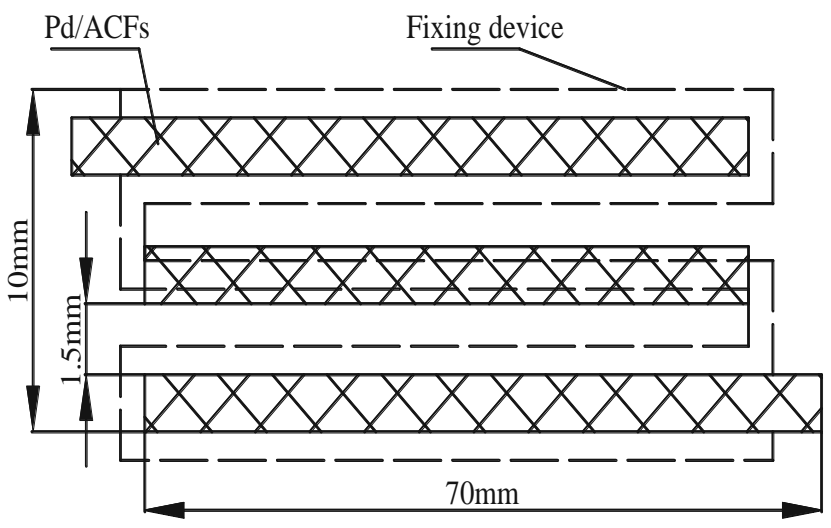

(c) 3 flat-type Pd/ACFs films unit

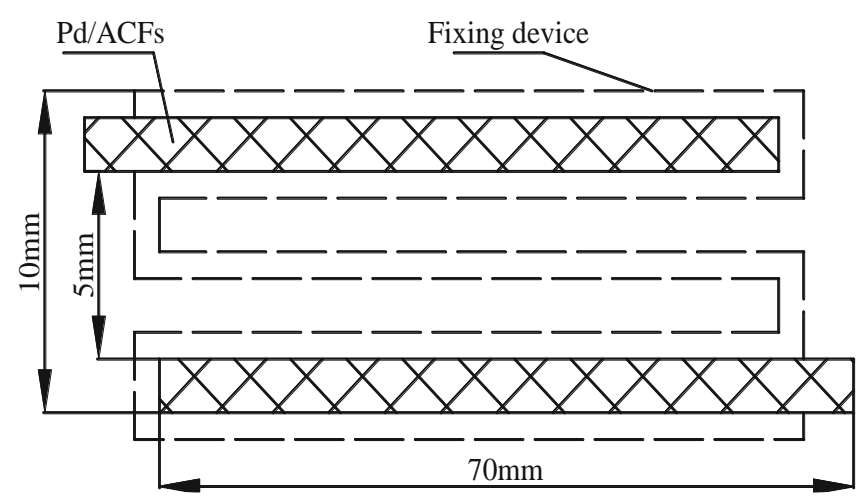

(b) 2 flat-type Pd/ACFs films unit

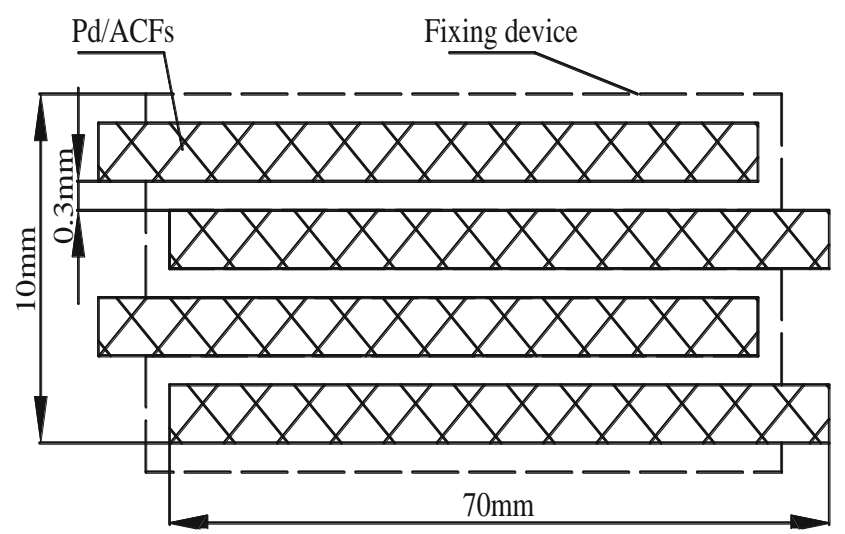

(d) 4 flat-type Pd/ACFs films unit

Figure 4. The detail of supporting components and ozone removal unit

\section{Results and Discussions}

\subsection{The Performance of Ozone Removal Unit}

\subsubsection{Ozone Removal}

Figure 5 shows the variation of the outlet ozone concentration with time for the three types of ozone removal units at the flow velocity of $0.3 \mathrm{~m} / \mathrm{s}$. At the time of $0 \mathrm{~min}$, ozone flowed into the by-pass Route I (in Figure 2) with the initial concentration of $1.79 \mathrm{ppm}$. After the ozone concentration reached steady for one hour, it was introduced into the reactor. Here, only the steady data of the first $40 \mathrm{~min}$ were indicated in the Figure 4 . The reaction temperature was increased with the rise rate of $40^{\circ} \mathrm{C}$ every $40 \mathrm{~min}$ from $40^{\circ} \mathrm{C}$ until it reaches $200^{\circ} \mathrm{C}$. One can see that the ozone concentration decreased quickly when the reaction temperature was increased. It also decreased sharply by the increasing reaction area. Ozone concentration dropped rapidly to the level of $0.22 \mathrm{ppm}$ and $0.08 \mathrm{ppm}$ at room temperature with 3 and 4 flattype Pd/ACFs films, respectively, while it was almost $0.99 \mathrm{ppm}$ with 2 flat-type Pd/ACFs films. However, the effect of reaction area on the ozone removal is not obvious with the rise in reaction temperature. For example, the outlet ozone concentration for all three types ozone removal unit were almost zero at the temperature of $200^{\circ} \mathrm{C}$. So the ozone removal over Pd/ACFs is dominated by the reaction temperature because the catalyst has the higher activity at the higher temperature.

The above results show that the ozone removal performance of the Pd/ACFs can be enhanced by increasing reaction area at lower temperature; otherwise the reaction temperature should be improved. Poshin et al. [27] evaluate the ozone removal over activated carbon filters at the ppb level of ozone concentration and found that the ozone removal capacity 
can be increased by increasing the contact surface area. The similar results were founded in this study. On the other hand, the more Pd/ACFs layers lead to the decreasing space of adjacent catalyst Pd/ACFs, which shorten the flow area of ozone and increase the flow velocity on the Pd/ACFs surface. Therefore, the ozone concentration boundary layer on the surface of $\mathrm{Pd} / \mathrm{ACF}$ become thin and the more ozone can be absorbed and decomposed.

Figure 6 shows the ozone conversion rate of the ozone removal unit with the different layers of Pd/ACFs film varies with temperature. The ozone conversion rate was calculated by $100\left(\mathrm{C}_{\mathrm{in}}-\mathrm{C}_{\text {out }}\right) / \mathrm{C}_{\mathrm{in}} \%$, where $\mathrm{C}_{\text {in }}$ and $\mathrm{C}_{\text {out }}$ is the inlet and outlet ozone concentration ( $\mathrm{ppm}$ ), respectively. The ozone conversion rate with three and four layers of catalyst $\mathrm{Pd} / \mathrm{ACF}$ was more than $90 \%$ at $40^{\circ} \mathrm{C}$ and further increased to $99 \%$ when the temperature reached at $200{ }^{\circ} \mathrm{C}$. However, for the two layers of Pd/ACFs, it was only $45 \%$ at room temperature, but over $97 \%$ when the temperature rose to $160^{\circ} \mathrm{C}$ and up to $99 \%$ at the temperature of $200{ }^{\circ} \mathrm{C}$. The results further illustrated that enhancing temperature was important for catalytic removal of ozone with the catalyst $\mathrm{Pd} / \mathrm{ACF}$.

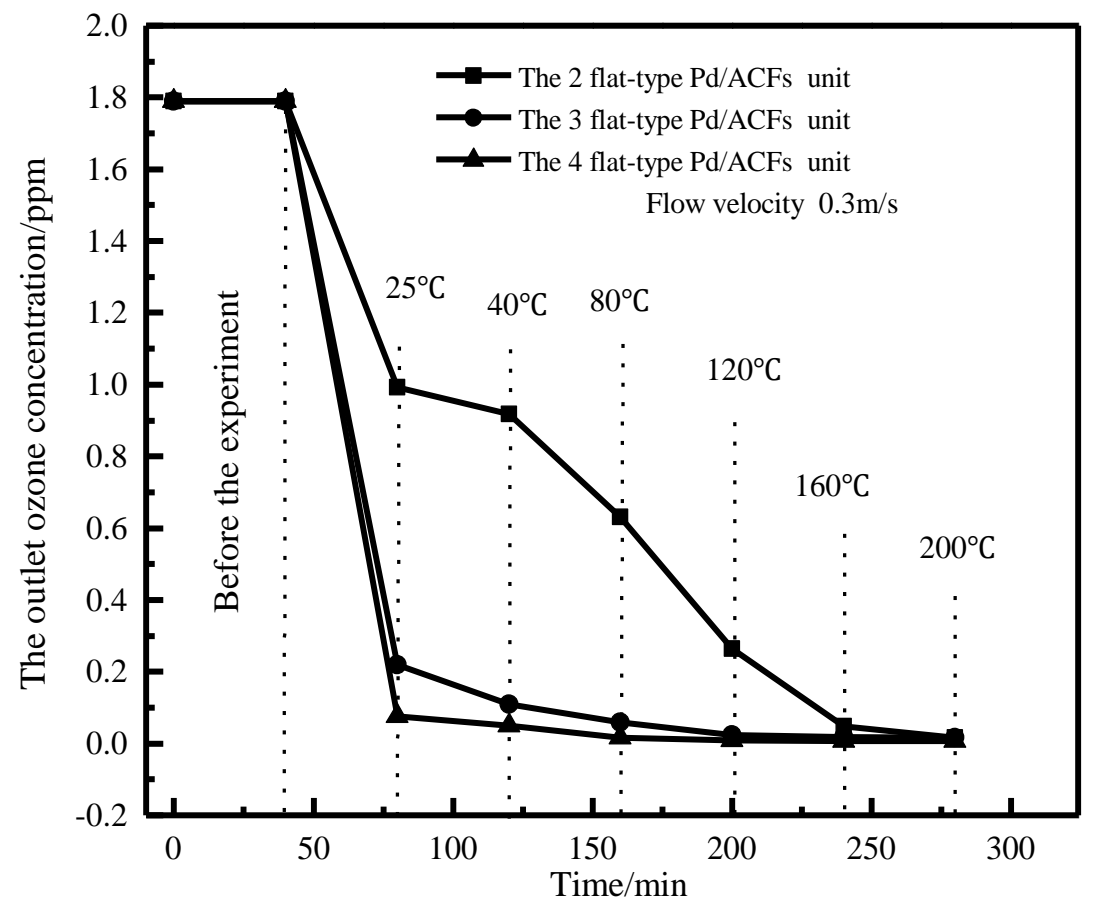

Figure 5. Variation of the outlet ozone concentration with time at different reaction temperature

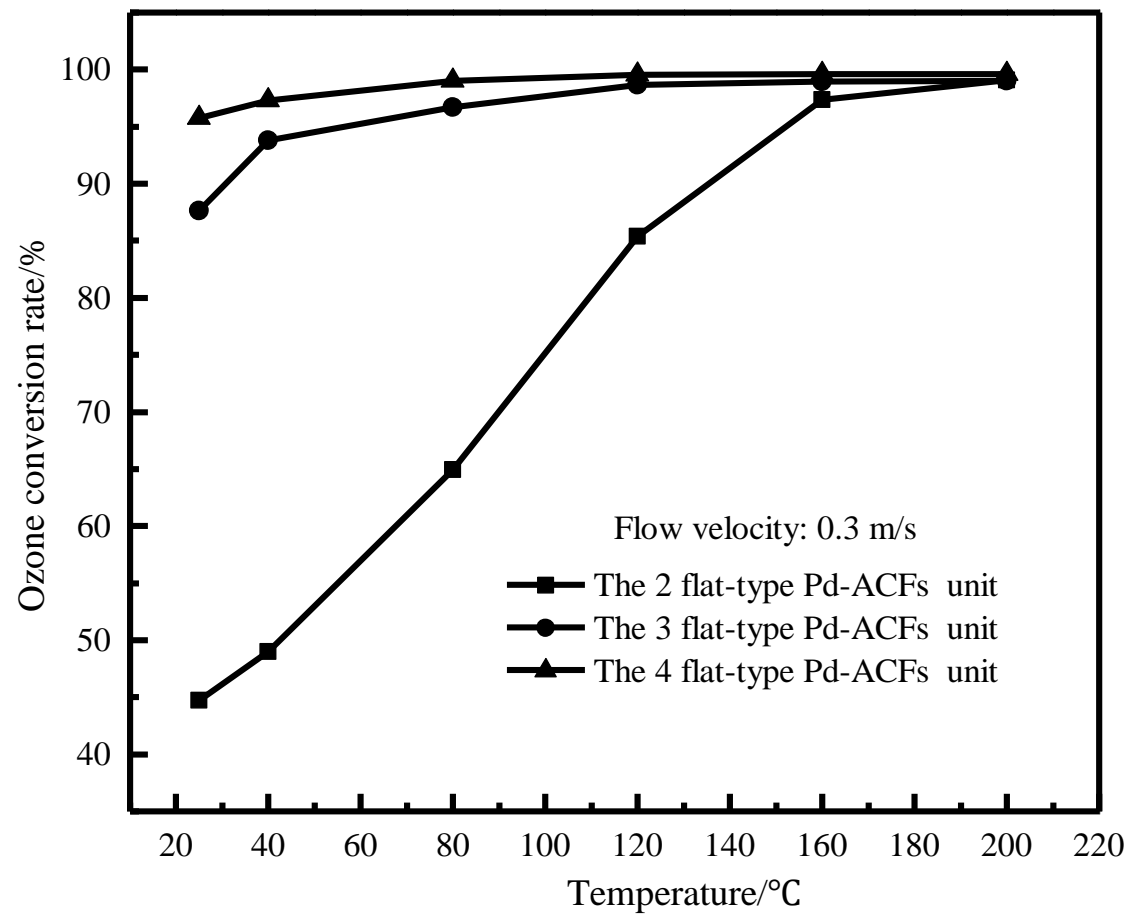

Figure 6. Variation of the ozone conversion rate with temperature using the different ozone removal units 


\subsubsection{The Pressure Drop of Ozone Removal Units}

The pressure drop is another important parameter for ozone reactor, for reducing energy consumption the lowpressure drop is recommended. The pressure drop in this research was measured by a U-tube manometer and calculated by the altitude difference of water column in the U-tube as Equation 1.

$$
\Delta P=\rho g h
$$

Where $\Delta P$ is the pressure drop of import and export reactor $(\mathrm{kPa}), \rho$ is the density of water column $\left(\mathrm{kg} / \mathrm{m}^{3}\right), g$ is the acceleration of gravity $\left(\mathrm{m} / \mathrm{s}^{2}\right), h$ is the height difference of water column in the U-tube manometer $(\mathrm{m})$.

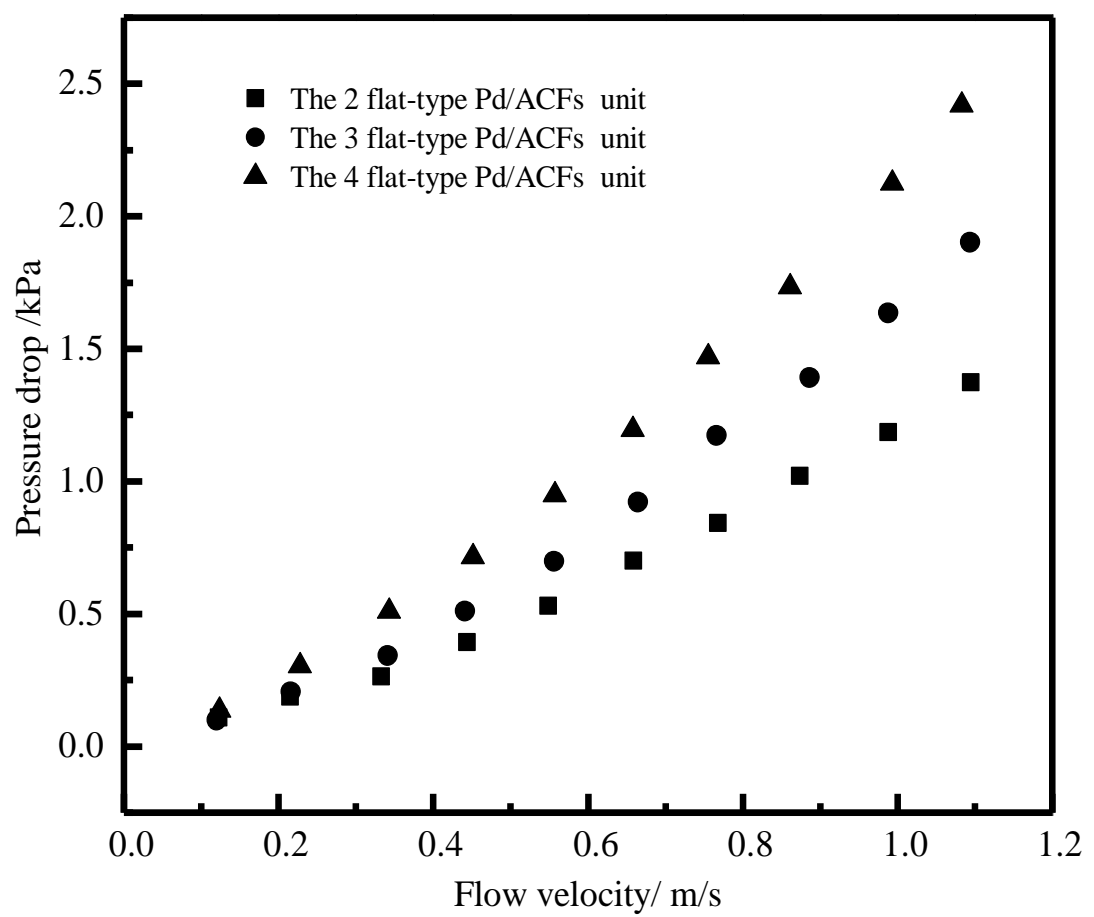

Figure 7. Variation of the pressure drop with flow velocity for the different ozone removal units

Figure 7 shows the variation of the pressure drop with flow velocity for the different ozone removal units. The pressure drop increased with the rose in flow velocity for the given ozone removal unit. It also increased with the rose in the number of catalyst layers at a fixed flow velocity. For example, the pressure drop in the ozone removal unit increased from $1.37 \mathrm{kPa}$ for 2 catalyst films to $2.42 \mathrm{kPa}$ for 4 catalyst layers at the flow velocity of $1.1 \mathrm{~m} / \mathrm{s}$. The reason is that the more Pd/ACFs layers filled in the reactor can lead to the smaller flow area of reactor and the higher flow velocity over the catalyst surface, which result in the higher on-way resistance. Shuai et al. [28] analyzed the pressure losses in automotive catalytic converter and found that the porosity of the packed bed has a significate impact on the pressure drop of the catalytic converter, the higher porosity of packed bed contribute to the lower pressure drop. The similar conclusion was also obtained in our study.

\subsubsection{The Pressure Drop Prediction}

The ozone reactor filled with catalyst $\mathrm{Pd} / \mathrm{ACF}$ is supposed as a porous media, so the porous media model can analyze the relationship between pressure drop and flow velocity. Regulski et.al studied the pressure drop in the porous media by numerical and experiment study and proposed the pressure drop prediction model as shown in Equation 2 [29].

$$
\frac{\Delta p}{\Delta L}=\frac{\mu}{k_{1}} U+\frac{\rho}{k_{2}} U^{2}
$$

Where $\Delta p / \Delta L$ is the average pressure gradient $(\mathrm{Pa} / \mathrm{m}) . \Delta L$ is the length of reactor $(\mathrm{m}) . U$ is the mean flow velocity through the reactor $(\mathrm{m} / \mathrm{s}), \rho$ is the fluid density $\left(\mathrm{kg} / \mathrm{m}^{3}\right), \mu$ is the fluid dynamic viscosity $\left(\mathrm{N} \cdot \mathrm{s} / \mathrm{m}^{2}\right)$, the coefficient $1 / k_{1}$ is viscous permeability $\left(1 / \mathrm{m}^{2}\right)$, and $1 / k_{2}$ is inertial permeability $(1 / \mathrm{m})$. In this research, the fluid density and fluid dynamic viscosity is $1.225 \mathrm{~kg} / \mathrm{m}^{3}$ and $17.9 \times 10^{-6} \mathrm{~N} \cdot \mathrm{s} / \mathrm{m}^{2}$, respectively.

For the porous bed composed of uniformly spaced structure, Ergun [30] and Edouard [31] had proposed the DarcyForcheimer formula, as shown below: 


$$
\begin{aligned}
& \frac{1}{k_{1}}=2.42 \frac{a_{c}^{2}}{\varepsilon^{3}} \\
& \frac{1}{k_{2}}=0.36 \frac{a_{c}}{\varepsilon^{3}} \\
& a_{c}=\frac{S_{s}}{V_{P d / A C F s}} \\
& \varepsilon=\frac{V_{\text {total }}-V_{P d / A C F s}}{V_{\text {total }}}
\end{aligned}
$$

Where $a_{\mathrm{c}}$ is the surface to volume ratio of $\mathrm{Pd} / \mathrm{ACFs}(1 / \mathrm{m}), \varepsilon$ is the external porosity (the internal porosity is negligible), $S_{\mathrm{s}}$ is the external surface area of Pd/ACFs $\left(\mathrm{m}^{2} / \mathrm{g}\right), V_{\mathrm{Pd} / \mathrm{ACFs}}$ is the external volume of $\mathrm{Pd} / \mathrm{ACFs}\left(\mathrm{m}^{3} / \mathrm{g}\right), V_{\text {total }}$ is the total volume of the ozone removal reactor $\left(\mathrm{m}^{3}\right)$.

In this research, $\mathrm{Ss}=0.15 \mathrm{~m}^{2} / \mathrm{g}$ and $\mathrm{VPd} / \mathrm{ACFs}=20 \times 10-6 \mathrm{~m}^{3} / \mathrm{g}$, so the ac $=7500 \mathrm{~m}^{-1}$. The external porosity of 2 to 4 flat-type ozone removal unit is $0.69,0.62$ and 0.57 , respectively. Therefore, the relationship between pressure drop gradient and Equations 6 to 8 can predict flow velocity for 2 to 4 flat-type ozone removal unit.

$$
\begin{aligned}
& \text { 2 flat-type: } \frac{\Delta p}{\Delta L}=7.417 U+10.07 U^{2} \\
& 3 \text { flat-type: } \frac{\Delta p}{\Delta L}=10.224 U+13.878 U^{2} \\
& \text { 4 flat-type: } \frac{\Delta p}{\Delta L}=13.157 U+17.859 U^{2}
\end{aligned}
$$

Figure 8 shows the comparison of pressure drop gradient between the experimental data and the predicting value of Equations 6 to 8, the maximum relative deviation is about 7.4\% that mainly comes from the ozone removal unit of 2 layers catalyst. While for the 3 and 4 layers catalyst film, the predicting value of pressure drop fits well with the experimental data. It can be seen that the pressure drop of ozone removal unit in this research can be predicted by DarcyForcheimer formula.

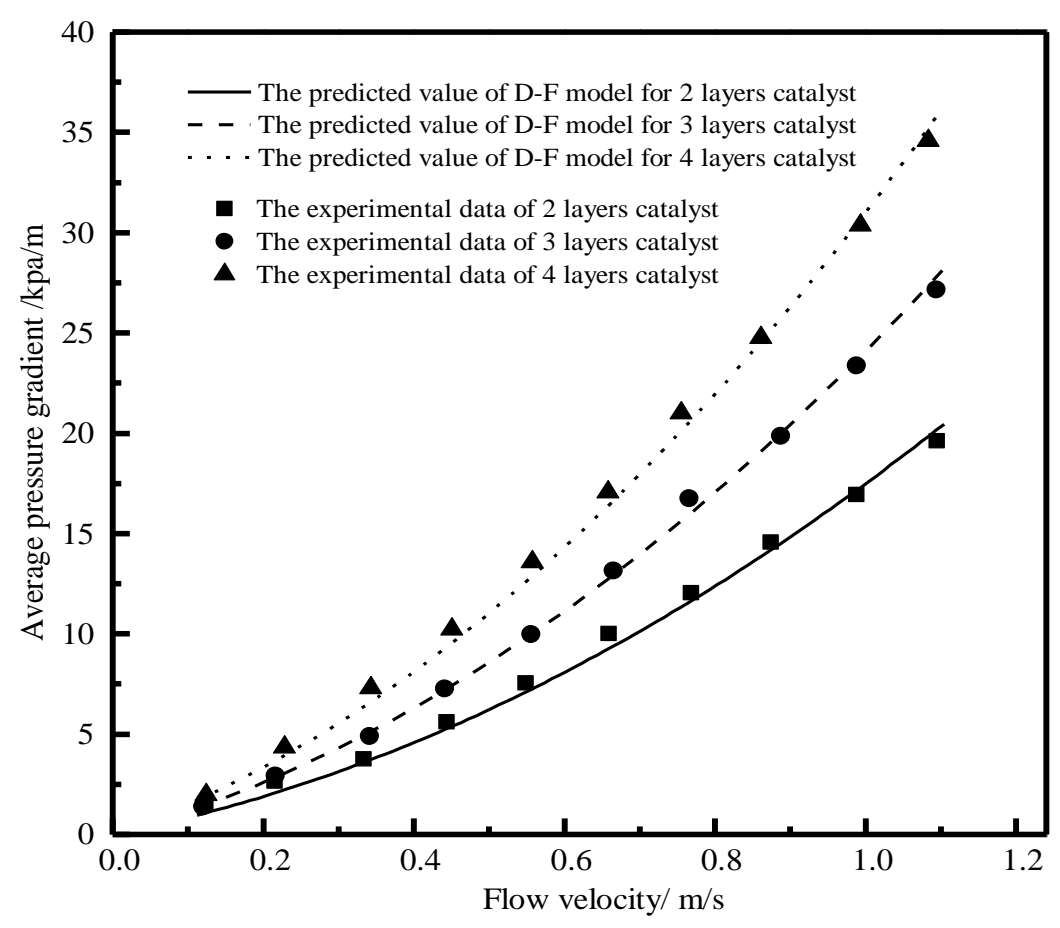

Figure 8. The fitted curves for flow velocity to pressure drop of three kinds of ozone removal unit 


\subsection{Ozone Converter Development and Performance Testing}

Figure 9 shows the typical modern aircraft ventilation system in the aircraft, the bleeding air is provided by the engine compressor, ozone removed by ozone converter, cooled by air-conditioning packs located under the wine center section, at last, the clean air was transformed to the cabin. Ozone converter is commonly installed in the aircraft underbody at the duct leading from jet engine compressor to the passenger cabin, it must have excellent ozone removal capability to meet the ozone concentration standards and low resistance to minimize the energy consumption [32, 33].

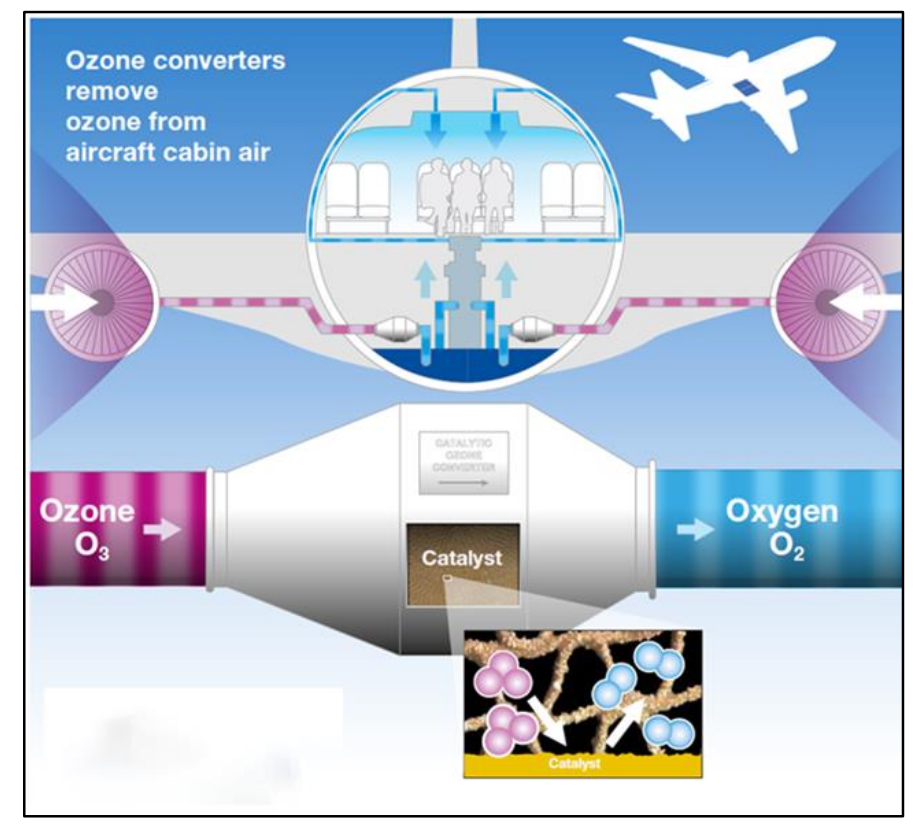

Figure 9. The typical ventilation system in the modern aircraft

A flat-type ozone reactor was designed and manufactured based on the above results, and it was housed in a cuboid converter with the dimension of $0.3 \times 0.3 \times 0.3 \mathrm{~m}^{3}$. Synthesizes the ozone conversion rate and pressure drop in above research, the catalyst film space of $1.5 \mathrm{~mm}$ was chosen for the design of ozone reactor.

\subsubsection{Ozone Converter Design}

Heck and his co-worker [34] proposed the design requirement for ozone converter in the wide body commercial aircraft after a detailed analysis of the in-flight performance. Chen et al. [35] simulate the ventilation of an aircraft cabin mockup with a real MD-82 commercial airliner, mentioned that the minimum air supply is $7.1 \mathrm{~L} /($ per.s) that is equal to $1232 \mathrm{~kg} / \mathrm{h}$ at the condition of $20^{\circ} \mathrm{C}$ and $1 \mathrm{~atm}$ in the aircraft cabin. This value can meet the ASHRAE standard [36]. Therefore, the designed size and performance evaluation index of the ozone converter is based on the parameters in Table 1.

Table 1. Range of design conditions for ozone converters in wide body aircraft

\begin{tabular}{lc}
\hline The minimum air flow $(\mathrm{kg} / \mathrm{h})$ & 1232 \\
Temperature $\left({ }^{\circ} \mathrm{C}\right)$ & $120-200$ \\
Pressure $(\mathrm{atm})$ & $1.6-4.0$ \\
Allowable pressure drop $(\mathrm{kPa})$ & $3.4-10.3$ \\
Required conversion $(\%)$ & $83-93$ \\
Housing diameter $(\mathrm{m})$ & $0.2-0.28$ \\
Housing length $(\mathrm{m})$ & $0.43-0.56$ \\
Maximum weight $(\mathrm{kg})$ & $9-16$ \\
\hline
\end{tabular}

A flat-type ozone reactor was designed, which was composed of an external framework and 17 flat-type catalyst units, the schematic diagram and photograph of ozone reactor are shown in Figures 10 and 11, respectively.

The external framework was welded by 12 stainless steel square tubes with the dimension of $0.3 \times 0.3 \times 0.3 \mathrm{~m}^{3} .17$ channels were reserved on the vertical square tubes for fixing the flat-type catalyst units. Each catalyst unit was made of a supporting plate and two layers of Pd/ACFs with the dimension of $290 \times 290 \times 8(\mathrm{~L} \times \mathrm{W} \times \mathrm{H}) \mathrm{mm}$, and the catalyst $\mathrm{Pd} / \mathrm{ACF}$ s were fixed on both side of the plate. 17 flat-type catalyst units were inserted into the channel on the framework to form the reactor, as shown in Figure 10. The space between the catalyst units is $1.5 \mathrm{~mm}$. 


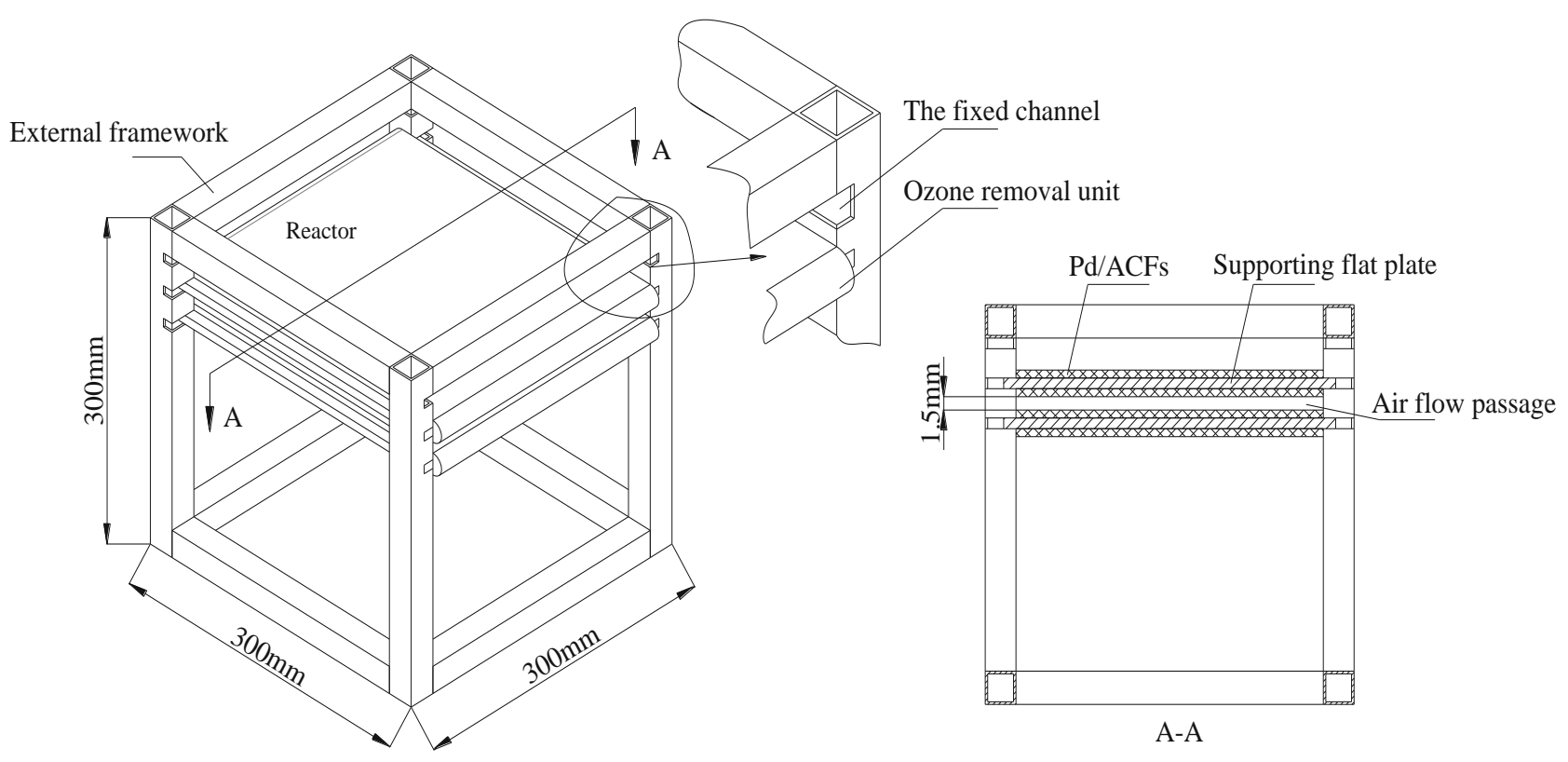

Figure 10. The schematic diagram of flat-type ozone reactor

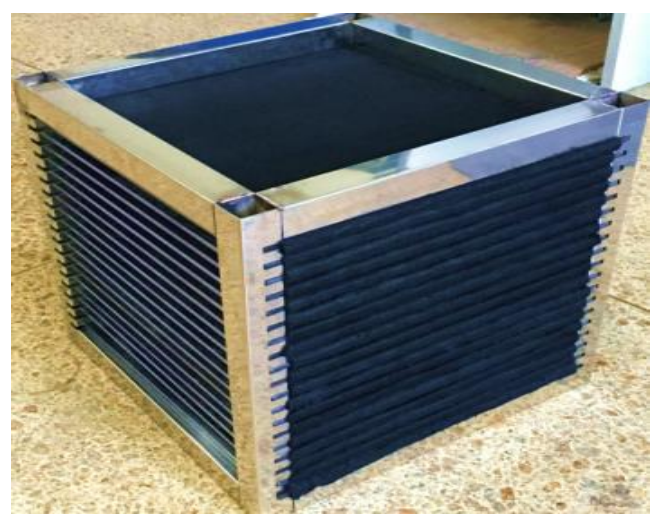

Figure 11. The photograph of flat-type ozone reactor

The reactor was housed with an entrance and outlet region to form an ozone converter, as shown in Figure 12. In general, the shape of air duct for the fresh bleeding air to the aircraft cabin is circular, so the ozone reactor is connected to the entrance and outlet region by the transition zone from column to square. The diameter and length of the entrance and outlet transition zone is $114 \mathrm{~mm}$ and $100 \mathrm{~mm}$, respectively, and the total housing length is $500 \mathrm{~mm}$.

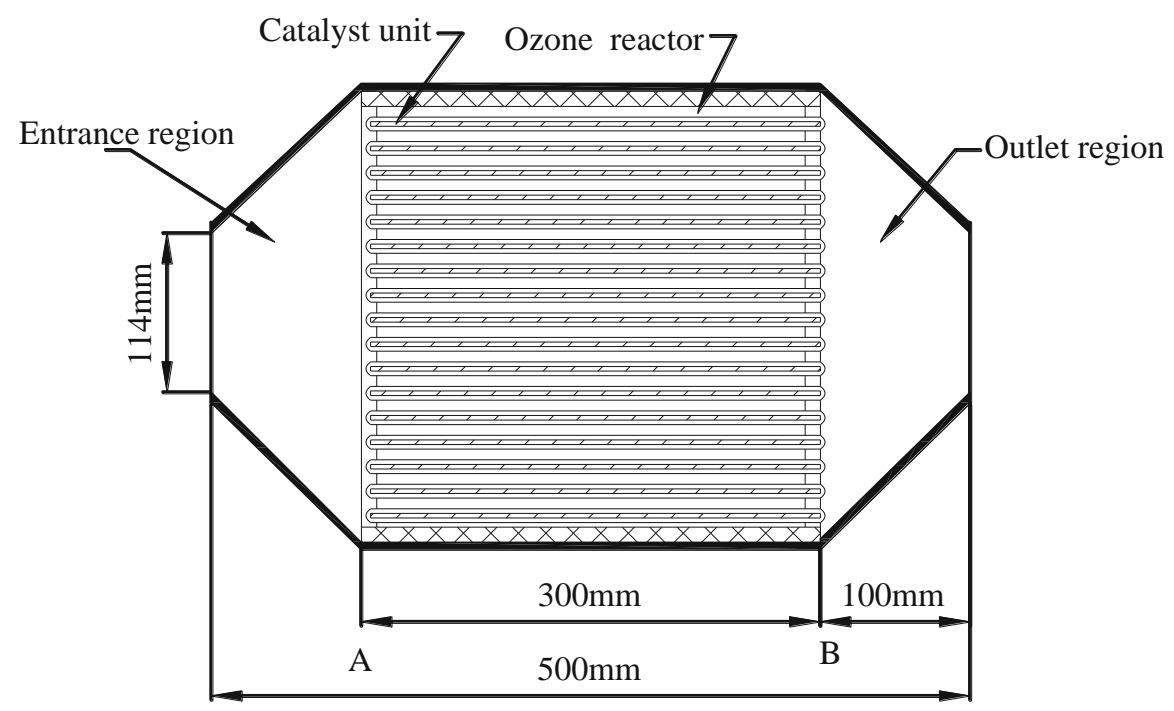

Figure 12. The sectional view of ozone converter 


\subsubsection{The Performance Test System of Ozone Converter}

Figure 13 shows the performance test system for the ozone converter, which was comprised of by-pass Route I and primary test Route II. The parameters of mass flow rate, reaction temperature and initial ozone concentration can be adjusted to simulate the fresh air condition of aircraft cabin.

The stable airflow comes from a high-pressure air source, which is equipped with an electrical heater to control the temperature of airstream. Because the outlet pressure of ozone generator is near to ambient pressure, ozone cannot be introduced into the high-pressure test section directly, so an ejector was equipped to introduce ozone easily.

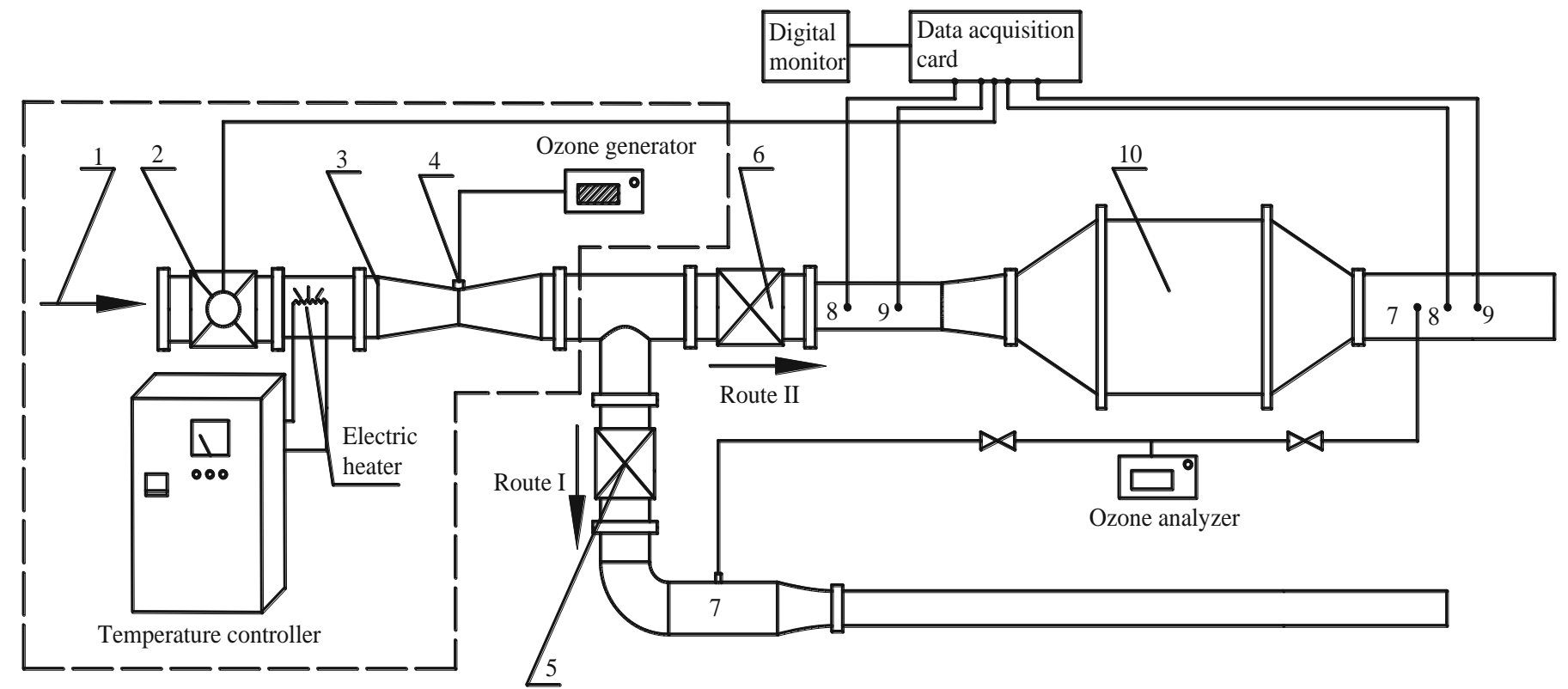

1. Air source 2. Mass flow controller 3.Ejector 4. The ozone entrance 5. Ball valve in Route I 6. Ball valve in Route II 7. The measure point of ozone concentration 8 . The pressure measurement point 9 . The temperature measurement point 10 . Ozone converter

\section{Figure 13. The test system for the performance of ozone converter}

The bleeding air that coming from the high pressure air source (1) was adjusted by a mass flowrate controller (2), and then which was heated to a given temperature by an electrical heater. An ozone generator was connected to the ozone entrance (4) that is located at the middle of ejector (3) to introduce the ozone into the system. Thus, a fixed flowrate of airstream with constant temperature and initial ozone concentration can flow into the ozone converter (5). Firstly, the ozone was introduced into the by-pass route I to steady the experimental parameters, and then it was introduced into the route II to test the performance of the ozone converter. The detailed information can be found in the literature [19]. The inlet and outlet ozone concentration were measured by an ozone analyzer (American 2B-technology 106-L with the precision: $0.1 \mathrm{ppb})$, the corresponding pressure and temperature were measured by pressure transducer (with the accuracy grade of $0.25 \%$ ) and temperature gauges (with the precision: $\pm 0.5^{\circ} \mathrm{C}$ ), respectively. All the testing data were recorded by a data acquisition instrument every 5 minutes.

\subsubsection{The Data Processing}

(1) The flow velocity in the ozone converter

The flow velocity $v$ through the ozone converter at each temperature $t$ and pressure $p$ can be obtained with Equation 9.

$$
v=\frac{G}{3600 \times \rho A}
$$

Where $G$ is the mass flow rate of the airstream $(\mathrm{kg} / \mathrm{h}), \rho$ is the density of airstream through the ozone converter at the fixed temperature and pressure $\left(\mathrm{kg} / \mathrm{m}^{3}\right), \mathrm{A}$ is the flow cross-sectional area in the designed ozone converter $(\mathrm{m})$, in this research, $\mathrm{A}=0.03 \mathrm{~m}^{2}$. The density $\rho$ can be obtained by Equation 10 .

$$
\rho=\rho_{0}\left(\frac{273}{273+t}\right) \times \frac{p}{0.1013}
$$

Where $\rho_{0}=1.29 \mathrm{~kg} / \mathrm{m}^{3}$. 
(2) The pressure drop of ozone converter

The pressure drop $(\Delta p)$ of the ozone converter was obtained by the inlet and outlet pressure difference $\left(p_{1}-p_{2}\right)$, where $p_{1}$ and $p_{2}$ are the inlet and outlet static pressure of ozone converter $(\mathrm{kPa})$, respectively.

(3) The minimum flow velocity in the ozone removal reactor

The minimum flow velocity was gotten by the minimum air supply of $7.1 \mathrm{~L} /(\mathrm{per} \cdot \mathrm{s})$ that is equal to $1232 \mathrm{~kg} / \mathrm{h}$ at the condition of $20^{\circ} \mathrm{C}$ and 1 atm, according to the Equation $10, \rho_{20}{ }^{\circ} \mathrm{C}=1.23 \mathrm{~kg} / \mathrm{m}^{3}$. The minimum flow velocity flow through the ozone reactor is $2.30 \mathrm{~m} / \mathrm{s}$.

\subsubsection{The Performance Test of Ozone Converter}

The ozone converter performance was tested under the mass flow rate of $306-680 \mathrm{~kg} / \mathrm{h}$ at the temperature of $20^{\circ} \mathrm{C}$, $90^{\circ} \mathrm{C}$ and $150^{\circ} \mathrm{C}$. The corresponding velocity range is $2.30-5.12,2.91-6.49$ and 3.14-7.00 m/s, respectively. So the flow velocity in experiment meets the flight requirements. For the commonly commercial airliner, the ozone concentration outside the aircraft cabin is in the range of 0.5-1 ppm at the cruising altitude [37], so the initial ozone concentration was $1 \mathrm{ppm}$ in this study.

\section{(1) Ozone removal performance}

Figure 14 shows the variation of the outlet ozone concentration with time over ACFs or Pd/ACFs at different flow velocity and temperature. At the time of $0 \mathrm{~min}$, ozone with different initial concentration was introduced into the system and labeled with a dash line. Figure 14(a) and (b) focus on the variation of ozone concentration at room temperature by using the ozone converter with ACFs and Pd/ACFs, respectively. Ozone concentration dropped quickly as soon as the airstream flow through the ozone converter. The outlet ozone concentration using ACFs decreased from 1.0 to 0.085 $\mathrm{ppm}$ at the flow velocity of $2.30 \mathrm{~m} / \mathrm{s}$, and it increased to $0.12 \mathrm{ppm}$ as the flow velocity rose to $5.12 \mathrm{~m} / \mathrm{s}$. While for the ozone converter with $\mathrm{Pd} / \mathrm{ACF}$, the outlet ozone concentration dropped to $0.13 \mathrm{ppm}$ after 40 min under the same experimental conditions, then it increased to $0.14 \mathrm{ppm}$ when the flow velocity increase to $5.12 \mathrm{~m} / \mathrm{s}$. Due to the nanoparticle catalyst palladium occupied the adsorption site of ACFs, the performance of ozone removal using Pd/ACFs seems to be weaker relative to the ACFs at the room temperature. Also, the effect of flow velocity on ozone removal is minor.
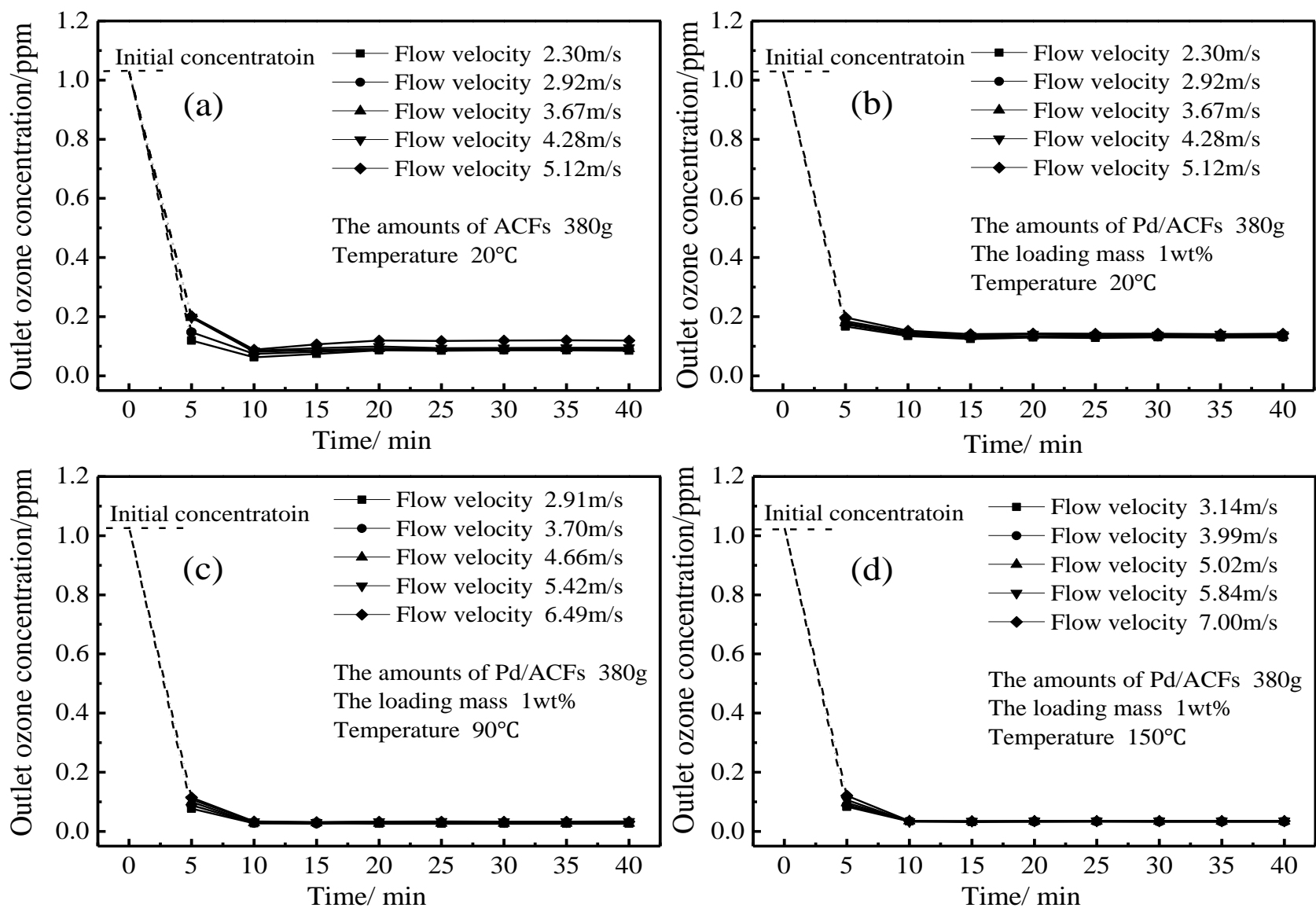

Figure 14. Variation of the ozone concentration with time at different flow velocity and temperature 
However, the performance of ozone removal increased obviously over Pd/ACFs with the increase in temperature, as show in Figure 14(c) and (d). The outlet ozone concentration was near to $0 \mathrm{ppm}$ at the temperature of 90 and $150^{\circ} \mathrm{C}$, then kept at this value in the rest process of experiment. The effect of flow velocity on the ozone removal is not obvious at the higher temperature. The reason is that the catalyst activity is excited and the catalytic reaction between ozone and $\mathrm{Pd} / \mathrm{ACF}$ is promoted by the higher temperature. Therefore, the control step for ozone removal at the higher temperature is mass transfer comparing with that in the lower temperature. The greater the flow velocity is, the more ozone molecules will transfer to the surface of Pd/ACFs and be decomposed.

Figure 15 shows the variation of the ozone conversion rate over ACFs and Pd/ACFs with flow velocity at different temperature. At each experimental condition, the corresponding mass flow rate is constant. The ozone conversion rate over ACFs and Pd/ACFs decreased with the increase in flow velocity at $20^{\circ} \mathrm{C}$. It decreased from $93 \%$ to $90 \%$ for ACFs and from $88 \%$ to $86 \%$ for Pd/ACFs, respectively, when flow velocity increased from 2.30 to $5.12 \mathrm{~m} / \mathrm{s}$. The ACFs shows a better ozone removal performance than that of $\mathrm{Pd} / \mathrm{ACFs}$ at $20^{\circ} \mathrm{C}$, the reason is that ozone removal mainly come from the adsorption of ACFs at room temperature. The nanoparticles palladium occupied the micro pore of ACFs and caused the decrease of adsorption surface area, which lead to the decreasing performance of ozone removal over $\mathrm{Pd} / \mathrm{ACFs}$. Katya Milenvoa et al. [38] studied the ozone removal by loading nanometer $\mathrm{Cu}$ and $\mathrm{TiO}_{2}$ on activated carbon and found that the specific surface areas of activated carbon decreased, which perhaps cause a poor ozone removal. The results were similar to our present study.

After raise the temperature, the performance of ozone conversion is significantly improved. However, the ozone conversion rate in $150^{\circ} \mathrm{C}$ is lower than it at $90^{\circ} \mathrm{C}$. The reason is that catalytic reaction is a surface reaction, ozone should contact with the catalyst, and then can be decomposed. For the Pd/ACFs, ozone must diffuse through the outer surface of ACF, then pass through the porous structure and interact with the palladium to complete the removal process. Though, the catalyst activity was promoted when the temperature is increased from $90^{\circ} \mathrm{C}$ to $150^{\circ} \mathrm{C}$ the properties of ozone desorption from ACFs was also enhanced. The promoted properties of ozone desorption has a more effect than the increasing catalytic activity on ozone removal at this condition. On the other hands, the flow velocity on the surface of catalyst at $150^{\circ} \mathrm{C}$ is higher than that at $90^{\circ} \mathrm{C}$ under the same mass flow rate, which leads to the less contact time of ozone over the catalyst $\mathrm{Pd} / \mathrm{ACFs}$. So the ozone conversion rate was lower at $150^{\circ} \mathrm{C}$ than that at $90^{\circ} \mathrm{C}$. Comparing the data in Table 1 , the flow velocity and ozone removal rate can meet design requirements.

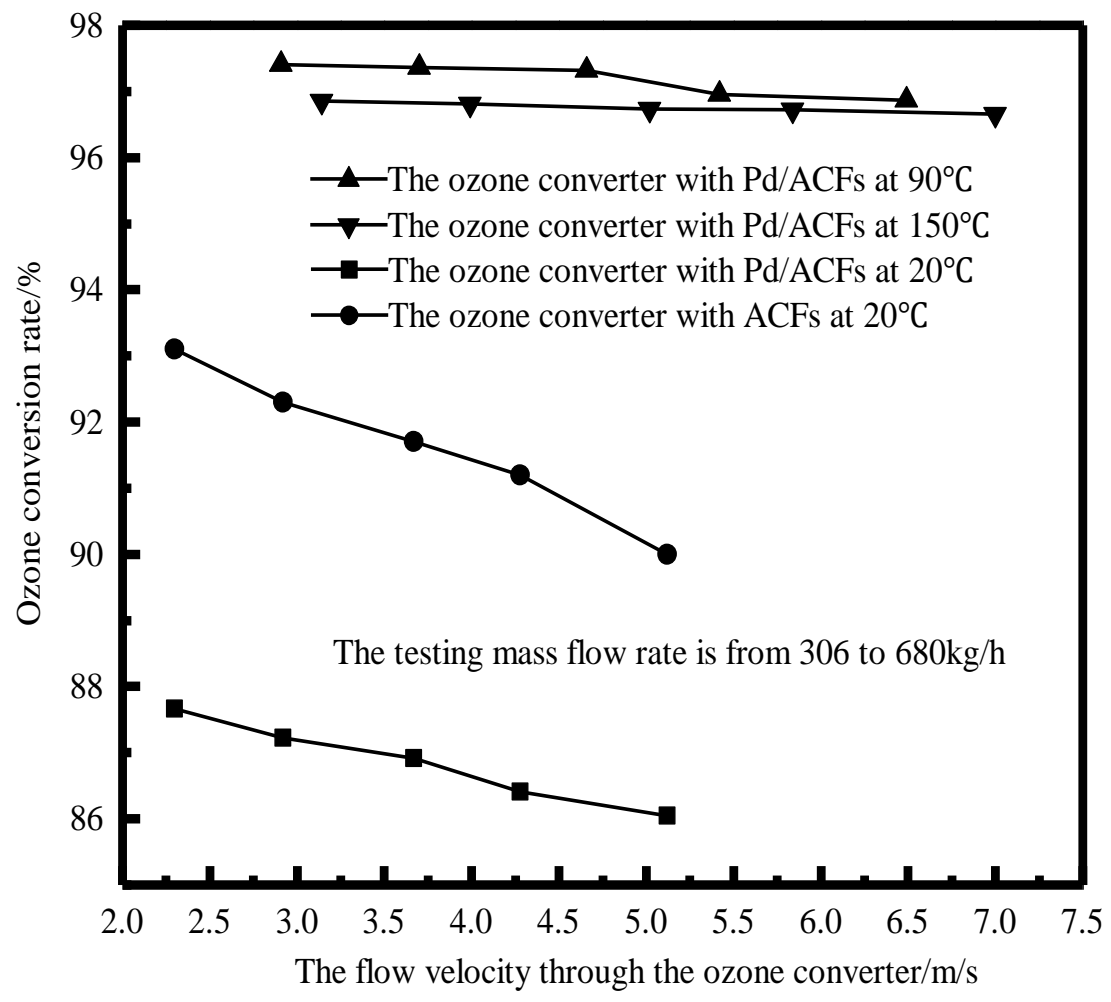

Figure 15. Variation of the ozone conversion over ACFs and Pd/ACFs with flow velocity at different temperature

(1) The pressure drop

The variation of experimental pressure drop in the ozone converter with different flow velocity was shown in the 
Figure 16. The corresponding mass flow rate was in the range of $311-1033 \mathrm{~kg} / \mathrm{h}$. It can be seen from the figure that the pressure drop increased with the increase in flow velocity, for example, the pressure drop promoted from $0.44 \mathrm{kPa}$ to $4.85 \mathrm{kPa}$ as the flow velocity increased from 2.40 to $7.97 \mathrm{~m} / \mathrm{s}$ at temperature of $20^{\circ} \mathrm{C}$. The maximum pressure drop of the ozone converter reached $6.44 \mathrm{kPa}\left(\right.$ at $90^{\circ} \mathrm{C}$ ) and $7.51 \mathrm{kPa}\left(\right.$ at $\left.150^{\circ} \mathrm{C}\right)$, respectively. The pressure drop of the designed ozone converter also meets the design requirements in Table 1.

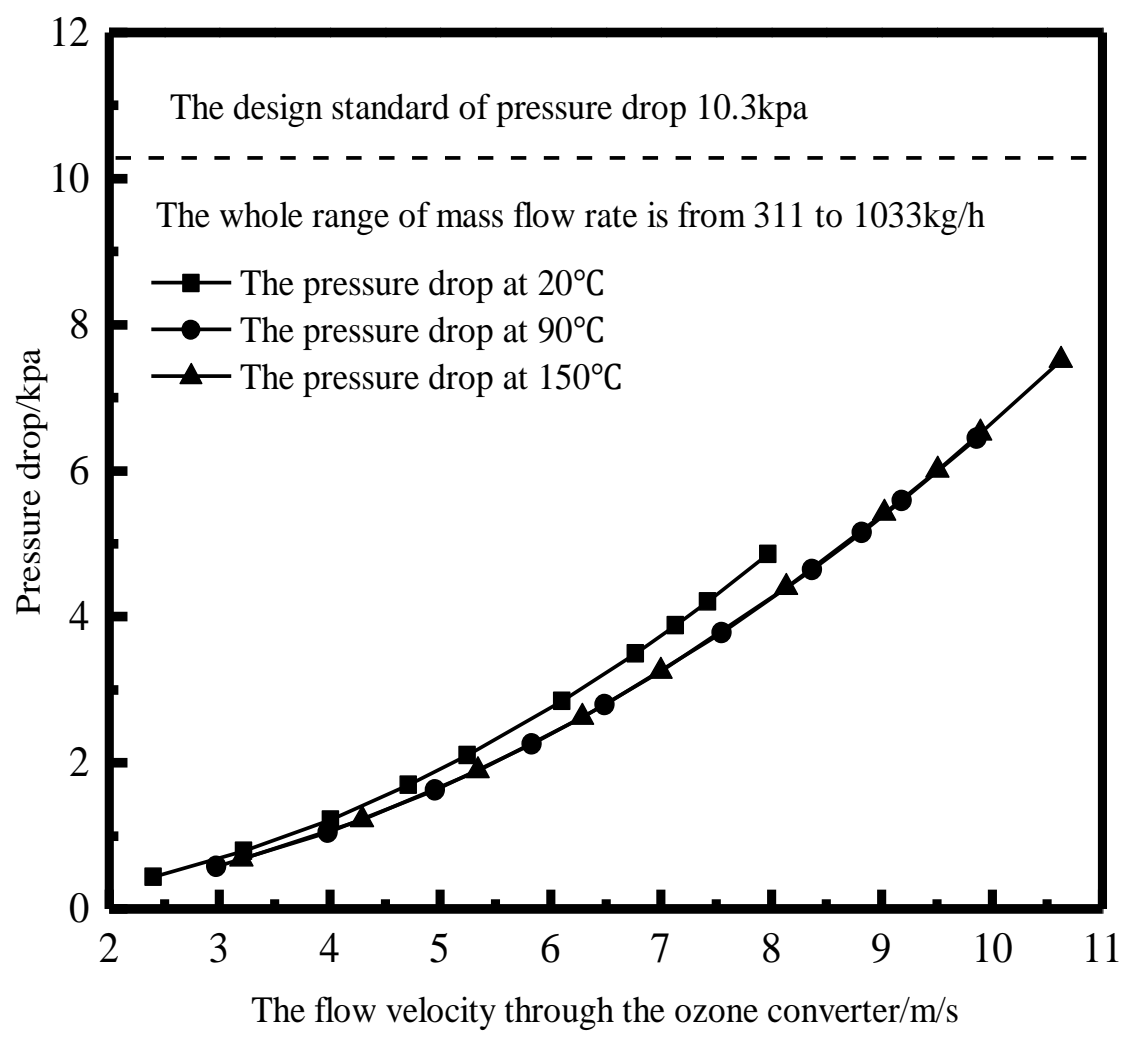

Figure 16. Variation of the pressure drop of the ozone converter with flow velocity

\subsection{The Limitation of This Study and the Outlook}

Although the designed ozone converter can meet the design property index of pressure drop and ozone conversion rate, the weight is $16.8 \mathrm{~kg}$ that is $0.8 \mathrm{~kg}$ heavier than the maximum weight in Table 1 . The construction materials of ozone converter can be substituted by the aluminum or other light materials in the future designed. On the other hands, the effect of temperature and flow velocity on the ozone removal performance was analyzed through experiment, due to the rigorous testing conditions, it is necessary to find the mathematical model and use the technique of computational fluid dynamics (CFD) to research the procession of ozone removal and optimal design of ozone converter in the future.

\section{Conclusion}

In this paper, three-arrangement type of flat catalyst film are used to experimentally explore the ozone removal performance, the influence of flow velocity and temperature on ozone removal capacity and flow resistance characteristic is studied in detail. Based on the above experimental results, the ozone removal unit with $1.5 \mathrm{~cm}$ space of $\mathrm{Pd} / \mathrm{ACF}$ that has an excellent performance to guides the design of ozone converter. At last, the prototype is tested through the testing system, which can simulate the actual work condition of aircraft cabin. From the present study, the following conclusion can be obtained:

- The one-trough ozone removal performance by catalyst Pd/ACFs films shows that the ozone removal unit with the space of $1.5 \mathrm{~cm}$ has an excellent ozone removal performance and low-pressure drop to meet the design requirement.

- The Darcy-Forchheimer model of the porous media can predict the pressure drop of the flat-type reactor in this study.

- The designed flat-type ozone converter has the ozone conversion of $97 \%$ and the maximum pressure drop of 7.51 $\mathrm{kPa}$ at the temperature of $150^{\circ} \mathrm{C}$ and flow velocity of $10.63 \mathrm{~m} / \mathrm{s}$, which can meet the ozone converter design requirements: The ozone conversion rate of $83-93 \%$ and the pressure drop of $3.4-10.3 \mathrm{kPa}$ 


\section{Funding}

The research presented in this paper is financially supported by the National Key Basic Research and Development Program of china (the "973" program) through grant No. 2012CB720102.

\section{Acknowledgment}

The authors are grateful to National natural science foundation of China for the financial support. The authors are also very much indebted to Dr. Jiang and Dr. Wang for the suggestion of setting up test system and preparation of the $\mathrm{Pd} / \mathrm{ACFs}$ catalysts, respectively.

\section{Conflicts of Interest}

The authors declare no conflict of interest.

\section{References}

[1] Wang, Jun, and Yong Chen. "Concentration Characteristics of Ozone and Product for Indoor Occupant Surface Chemical Reaction under Displacement Ventilation.” Energy and Buildings 130 (October 2016): 378-387. doi:10.1016/j.enbuild.2016.08.065.

[2] Bekö, Gabriel, Joseph G. Allen, Charles J. Weschler, Jose Vallarino, and John D. Spengler. "Impact of Cabin Ozone Concentrations on Passenger Reported Symptoms in Commercial Aircraft." Edited by Qinghua Sun. PLOS ONE 10, no. 5 (May 26, 2015): e0128454. doi:10.1371/journal.pone.0128454.

[3] Čavka, Ivana, Olja Čokorilo, and Ljubiša Vasov. "Energy Efficiency in Aircraft Cabin Environment: Safety and Design.” Energy and Buildings 115 (March 2016): 63-68. doi:10.1016/j.enbuild.2015.01.015.

[4] Bhangar, Seema, and William W Nazaroff. "Atmospheric Ozone Levels Encountered by Commercial Aircraft on Transatlantic Routes.” Environmental Research Letters 8, no. 1 (January 16, 2013): 014006. doi:10.1088/1748-9326/8/1/014006.

[5] Tashkin, Donald P., Anne H. Coulson, Michael S. Simmons, and Gary H. Spivey. "Respiratory Symptoms of Flight Attendants during High-Altitude Flight: Possible Relation to Cabin Ozone Exposure." International Archives of Occupational and Environmental Health 52, no. 2 (July 1983): 117-137. doi:10.1007/bf00405416.

[6] M. Amann, D. Derwent, B. Forsberg, O. Hänninen, F. Hurley, M. Krzyzanowski, F.D. Leeuw, S.J. Liu, C. Mandin, J. Schneider, Health risks of ozone from long-range transboundary air pollution, (2008).

[7] Gao, Kai, Jiarong Xie, and Xudong Yang. "Estimation of the Contribution of Human Skin and Ozone Reaction to Volatile Organic Compounds (VOC) Concentration in Aircraft Cabins." Building and Environment 94 (December 2015): 12-20. doi:10.1016/j.buildenv.2015.07.022.

[8] Lian, Zhihua, Jinzhu Ma, and Hong He. "Decomposition of High-Level Ozone under High Humidity over Mn-Fe Catalyst: The Influence of Iron Precursors.” Catalysis Communications 59 (January 2015): 156-160. doi:10.1016/j.catcom.2014.10.005.

[9] Kaminskii, Vladimir, Elena Kossovich, Svetlana Epshtein, Liudmila Obvintseva, and Valeria Nesterova. "Activity of Coals of Different Rank to Ozone.” AIMS Energy 5, no. 6 (2017): 960-973. doi:10.3934/energy.2017.6.960.

[10] Lu, Yuanwei, Xiaohua Zhao, Mingyuan Wang, Zhilong Yang, XingJuan Zhang, and Chunxin Yang. "Feasibility Analysis on Photocatalytic Removal of Gaseous Ozone in Aircraft Cabins.” Building and Environment 81 (November 2014): 42-50. doi:10.1016/j.buildenv.2014.05.024.

[11] Yuille, Lindsay, Denise Bryant-Lukosius, Ruta Valaitis, and Lisa Dolovich. "Optimizing Registered Nurse Roles in the Delivery of Cancer Survivorship Care within Primary Care Settings.” Canadian Journal of Nursing Leadership 29, no. 4 (December 6, 2106): 46-58. doi:10.12927/cjnl.2016.24984.

[12] Rai, Aakash C., and Qingyan Chen. "Simulations of Ozone Distributions in an Aircraft Cabin Using Computational Fluid Dynamics.” Atmospheric Environment 54 (July 2012): 348-357. doi:10.1016/j.atmosenv.2012.02.010.

[13] "The Airliner Cabin Environment and the Health of Passengers and Crew" (January 3, 2002). doi:10.17226/10238.

[14] Fadeyi, Moshood Olawale. "Ozone in Indoor Environments: Research Progress in the Past 15 Years." Sustainable Cities and Society 18 (November 2015): 78-94. doi:10.1016/j.scs.2015.05.011.

[15] Yu, Quanwei, Hao Pan, Ming Zhao, Zhimin Liu, Jianli Wang, Yaoqiang Chen, and Maochu Gong. "Influence of Calcination Temperature on the Performance of Pd-Mn/SiO2-A12O3 Catalysts for Ozone Decomposition.” Journal of Hazardous Materials 172, no. 2-3 (December 2009): 631-634. doi:10.1016/j.jhazmat.2009.07.040. 
[16] Nikolov, Penko, Krassimir Genov, Petya Konova, Katya Milenova, Todor Batakliev, Vladimir Georgiev, Narendra Kumar, Dipak K. Sarker, Dimitar Pishev, and Slavcho Rakovsky. "Ozone Decomposition on Ag/SiO2 and Ag/clinoptilolite Catalysts at Ambient Temperature.” Journal of Hazardous Materials 184, no. 1-3 (December 2010): 16-19. doi:10.1016/j.jhazmat.2010.07.056.

[17] Tatibouët, Jean-Michel, Sabine Valange, and Houcine Touati. "Near-Ambient Temperature Ozone Decomposition Kinetics on Manganese Oxide-Based Catalysts.” Applied Catalysis A: General 569 (January 2019): 126-133. doi:10.1016/j.apcata.2018.10.026.

[18] YU, Quanwei, Ming ZHAO, Zhimin LIU, Xiaoyu ZHANG, Lingmin ZHENG, Yaoqiang CHEN, and Maochu GONG. "Catalytic Decomposition of Ozone in Ground Air by Manganese-Based Monolith Catalysts." Chinese Journal of Catalysis 30 , no. 1 (January 2009): 1-3. doi:10.1016/s1872-2067(08)60082-0.

[19] Wang, Xin, Xin Tan, and Tao Yu. "Kinetic Study of Ozone Photocatalytic Decomposition Using a Thin Film of TiO2 Coated on a Glass Plate and the CFD Modeling Approach.” Industrial \& Engineering Chemistry Research 53, no. 19 (April 30, 2014): 7902-7909. doi:10.1021/ie403144w.

[20] Jodzis, Sławomir, and Tobiasz Barczyński. “Ozone Synthesis and Decomposition in Oxygen-Fed Pulsed DBD System: Effect of Ozone Concentration, Power Density, and Residence Time.” Ozone: Science \& Engineering 41, no. 1 (August 10, 2018): 6979. doi:10.1080/01919512.2018.1506317.

[21] R.Q. Liu, M. Zhao, R.F. Wang, Supported Metal Oxide Catalysts for Ozone Decomposition, Jiangsu Environmental Science \& Technology, (2008).

[22] Schaub, R., P. Thostrup, N. Lopez, E. Lægsgaard, I. Stensgaard, J. K. Nørskov, and F. Besenbacher. "Oxygen Vacancies as Active Sites for Water Dissociation on RutileTiO2(110).” Physical Review Letters 87, no. 26 (December 6, 2001). doi:10.1103/physrevlett.87.266104.

[23] Wu, Fan, Mingyuan Wang, Yuanwei Lu, Xingjuan Zhang, and Chunxin Yang. "Catalytic Removal of Ozone and Design of an Ozone Converter for the Bleeding Air Purification of Aircraft Cabin.” Building and Environment 115 (April 2017): 25-33. doi:10.1016/j.buildenv.2017.01.007.

[24] CHEN, Bingyan, Xiangxiang GAO, Ke CHEN, Changyu LIU, Qinshu LI, Wei SU, Yongfeng JIANG, Xiang HE, Changping ZHU, and Juntao FEI. "Regulation Characteristics of Oxide Generation and Formaldehyde Removal by Using Volume DBD Reactor.” Plasma Science and Technology 20, no. 2 (December 21, 2017): 024009. doi:10.1088/2058-6272/aa9b7a.

[25] Xu, Zhonglin. “Operational Property of Air Purifier.” Air Purifier (September 4, 2018): 51-63. doi:10.1007/978-981-13-25328 8.

[26] Heisig, Christopher, Weimin Zhang, and S.Ted Oyama. "Decomposition of Ozone Using Carbon-Supported Metal Oxide Catalysts.” Applied Catalysis B: Environmental 14, no. 1-2 (December 1997): 117-129. doi:10.1016/s0926-3373(97)00017-9.

[27] Lee, Poshin, and Jane Davidson. "Evaluation of Activated Carbon Filters for Removal of Ozone at the PPB Level." American Industrial Hygiene Association Journal 60, no. 5 (September 1999): 589-600. doi:10.1080/00028899908984478.

[28] S.J. Shuai, J.X. Wang, R.J. Zhuang, Pressure losses in automotive catalytic converters, Journal of Tsinghua University, (2001).

[29] Regulski, W., J. Szumbarski, Ł. Łaniewski-Wołłk, K. Gumowski, J. Skibiński, M. Wichrowski, and T. Wejrzanowski. "Pressure Drop in Flow Across Ceramic foams-A Numerical and Experimental Study." Chemical Engineering Science 137 (December 2015): 320-337. doi:10.1016/j.ces.2015.06.043.

[30] Ergun S. Fluid flow through packed columns[J]. Chemical Engineering Progress, 1952, 48(2): 89-94

[31] Edouard, David, Maxime Lacroix, Cuong Pham Huu, and Francis Luck. "Pressure Drop Modeling on SOLID Foam: State-ofthe Art Correlation.” Chemical Engineering Journal 144, no. 2 (October 2008): 299-311. doi:10.1016/j.cej.2008.06.007.

[32] Weisel, Clifford, Charles J. Weschler, Kris Mohan, Jose Vallarino, and John D. Spengler. "Ozone and Ozone Byproducts in the Cabins of Commercial Aircraft." Environmental Science \& Technology 47, no. 9 (April 5, 2013): 4711-4717. doi:10.1021/es3046795.

[33] Ronald M. Heck, Robert J. Farrauto, Suresh T. Gulati “Ozone Abatement Within Jet Aircraft." Catalytic Air Pollution Control (April 11, 2012): 357-373. doi:10.1002/9781118397749.ch10.

[34] Heck, R.M., R.J. Farrauto, and H.C. Lee. "Commercial Development and Experience with Catalytic Ozone Abatement in Jet Aircraft.” Catalysis Today 13, no. 1 (March 1992): 43-58. doi:10.1016/0920-5861(92)80186-q.

[35] Chen, Wenhua, Junjie Liu, Fei Li, Xiaodong Cao, Jiayu Li, Xueliang Zhu, and Qingyan Chen. "Ventilation Similarity of an Aircraft Cabin Mockup with a Real MD-82 Commercial Airliner." Building and Environment 111 (January 2017): 80-90. doi:10.1016/j.buildenv.2016.10.017. 
[36] “ASHRAE Publishes Residential Air Quality Standard.” Filtration \& Separation 44, no. 8 (October 2007): 6. doi:10.1016/s00151882(07)70224-0.

[37] Bhangar, Seema, Shannon C. Cowlin, Brett C. Singer, Richard G. Sextro, and William W. Nazaroff. "Ozone Levels in Passenger Cabins of Commercial Aircraft on North American and Transoceanic Routes.” Environmental Science \& Technology 42, no. 11 (June 2008): 3938-3943. doi:10.1021/es702967k.

[38] Milenova, K, Nikolov, P. , Stambolova, I. , Nikolov, P. , Blaskov, V.. "Carbon Supported Cu and TiO2 Catalysts Applied for Ozone Decomposition". World Academy of Science, Engineering and Technology, International Science Index, Environmental and Ecological Engineering (2015), 9(3), 493. 